\title{
Interference in native and non-native sentence processing
}

Article

Accepted Version

Cunnings, I. (2017) Interference in native and non-native sentence processing. Bilingualism: Language and Cognition, 20 (4). pp. 712-721. ISSN 1469-1841 doi:

https://doi.org/10.1017/S1366728916001243 Available at https://centaur.reading.ac.uk/68744/

It is advisable to refer to the publisher's version if you intend to cite from the work. See Guidance on citing.

To link to this article DOI: http://dx.doi.org/10.1017/S1366728916001243

Publisher: Cambridge University Press

All outputs in CentAUR are protected by Intellectual Property Rights law, including copyright law. Copyright and IPR is retained by the creators or other copyright holders. Terms and conditions for use of this material are defined in the End User Agreement.

\section{www.reading.ac.uk/centaur}

\section{CentAUR}

Central Archive at the University of Reading

Reading's research outputs online 
Running Head: Bilingual Sentence Processing

\title{
Interference in Native and Non-Native Sentence Processing
}

\author{
Ian Cunnings
}

University of Reading, UK

Address for correspondence:

Dr Ian Cunnings

School of Psychology and Clinical Language Sciences

University of Reading

Reading, UK

RG6 7BE

Email: $\quad$ i.cunnings @ reading.ac.uk

Phone: $\quad$ +44 (0)118 3785538 
The primary aim of my target article was to demonstrate how careful consideration of the working memory operations that underlie successful language comprehension is crucial to our understanding of the similarities and differences between native (L1) and non-native (L2) sentence processing. My central claims were that highly proficient L2 speakers construct similarly specified syntactic parses as L1 speakers, and that differences between L1 and L2 processing can be characterised in terms of L2 speakers being more prone to interference during memory retrieval operations. In explaining L1/L2 differences in this way, I argued a primary source of differences between L1 and L2 processing lies in how different populations of speakers weight cues that guide memory retrieval.

I am pleased that commentators agreed that this approach provides a useful way of examining language comprehension in monolingual and bilingual speakers. Commentaries focused broadly on issues related to the implementation of different memory retrieval cues during parsing and the question of why certain cues are more heavily weighted by L2 learners, the predictions of the interference account that I proposed, potential alternative accounts of L1 and L2 processing and the role of individual differences in both monolingual and bilingual comprehension. It is impossible to do full justice to the full range of comments, but below I discuss these main issues in turn.

\section{Retrieval cues in sentence processing}

A precise characterisation of the cues utilised to guide retrieval during language comprehension is crucial to cue-based parsing models. To address questions raised regarding what constitutes a retrieval cue (Juffs), I begin by outlining different retrieval cues in more detail.

In cue-based parsing (e.g. Lewis, Vasishth \& Van Dyke, 2006), items encountered during sentence processing are stored as chunks in memory that encode features about their properties. Subsequent items may cue retrieval of these prior chunks, based on the feature-match between a 
set of cues at retrieval and the features encoded in items in memory. Encoded features and cues relevant for retrieval can be drawn from a number of different sources. Firstly, cues can be drawn from the properties of lexical items, including semantic features (e.g. animacy; van Dyke, 2007) and morphosyntactic agreement features, such as number, as exemplified in agreement attraction (Wagers, Lau \& Phillips, 2009). Other cues are likely drawn from the local syntactic and semantic context. During parsing constituents may be encoded in memory with syntactic features such as [+SUBJECT] or [+OBJECT] (and/or corresponding features based on semantic or discourse representations, e.g. [+AGENT], [+TOPIC]), which can subsequently be targeted via retrieval cues (for evidence of subjecthood guiding retrieval, see van Dyke, 2007). Generally, cue-based models can easily utilise as cues information that can be encoded as features. What is not easily encoded as a feature however is relational information between items in memory (Alcocer \& Phillips, 2012; Kush, 2013). The most obvious implication of this for language relates to c-command (Reinhart, 1983). C-command is a relationship between sentence constituents based on the notion of hierarchical dominance which plays an important role in describing constraints on linguistic dependencies. For example, c-command plays a crucial role in Chomsky's (1981) characterisation of constraints on reflexives and pronouns. In (1), coindexation is only possible between a reflexive and a local, c-commanding antecedent. In this case, 'the man' is ruled out because it does not c-command the reflexive.

(1) The boy that the man saw yesterday injured himself.

One might hypothesise that reflexives cue retrieval of items with a [+C-COMMAND] feature, favouring retrieval of 'the boy' over 'the man'. However, items cannot simply be encoded as [+/-C-COMMAND]. For example, 'the man' cannot simply have a [-CCOMMAND] feature, as although this constituent does not c-command the reflexive, it does c- 
command other constituents in the sentence ('saw yesterday'). It is this relation between constituents that defines c-command, and this cannot be directly encoded as a feature.

Thus, even if L1 and L2 speakers construct structurally well-specified parses, cue-based retrieval cannot in any obvious way utilise [+/-C-COMMAND] as a memory retrieval cue. To overcome this issue, more abstract cues that utilise feature-based proxies to c-command need to be implemented. During parsing antecedents in (1) may be encoded with a feature marking them as being in a particular clause. For example, 'the boy' may be marked [+MAIN] (or [+CLAUSE1]), and then when the reflexive is encountered, it too is marked as being within this clause. This information, along with other relevant cues (e.g. [+MASC], [+SUBJECT]), can then guide retrieval. Other abstract features are also likely required to fully characterise constraints on linguistic dependencies (see Alcocer \& Phillips, 2012; Cunnings, Patterson \& Felser, 2015; Kush, 2013; Kush, Lidz \& Phillips, 2015). It is not possible here to describe the full range of cues required during language processing in more detail, but the point to be made is that retrieval cues will include both features drawn from lexical items, and other increasingly abstract cues that need to be drawn from the sentence structure. Even if L2ers compute elaborate sentence structure, they may not implement retrieval cues drawn from this structure in the same way as L1ers. For reflexives, being able to compute the relevant clause structure may be separate from implementing the relevant structure-based retrieval cues in a native-like way. Successful L2 processing thus requires knowledge of the relevant features that need to be encoded in sentence chunks in memory, and the ability to implement a set of retrieval cues that can discriminate between these items successfully.

Some commentators questioned how discourse-based cues are implemented (Dillon; Gabriele, Fiorentino \& Covey; Jacob, Lago \& Patterson; Kaiser; Malko, Ehrenhofer \& Phillips). For reflexives, Dillon (Dillon) noted difficulty in teasing apart whether the results of Felser and Cunnings (2012) suggest overreliance of a [+TOPIC] or a [+SUBJECT] cue. Both Dillon 
(Dillon) and Kaiser (Kaiser) also more generally discussed how syntactic, semantic and discourse-level cues are often correlated (e.g. subject, agent, topic) and difficult to dissociate empirically. I agree that further systematic research is required to examine these issues , and that it is currently difficult to tease apart whether the Felser and Cunnings' data result from a [+SUBJECT] or [+TOPIC] cue. However this cue is characterised, Felser and Cunnings' results nevertheless suggest L2ers weighted it more heavily during early retrieval processes for reflexives than L1 speakers.

Jacob et al. queried how a [+TOPIC] cue is implemented, arguing that antecedents only become topics once referred to with a pronoun. It may be that initially encountered constituents are first encoded as topics, and that pronouns then include a [+TOPIC] cue (amongst others) to guide retrieval to the topic. Malko et al. alternatively questioned how overt pronouns in null subject languages cue retrieval of non-topic antecedents. In this case, it might be that the set of retrieval cues include various syntactic/semantic/discourse-level cues with the exception of [+TOPIC], to guide retrieval to the next most salient antecedent other than the current topic. L2 misinterpretation in such cases (Sorace \& Filiaci, 2006) might thus be related to erroneously including [+TOPIC] in the set of retrieval cues for pronouns that should favour non-topics. Gabriele et al. noted that shifts in discourse topics may involve reanalysis. For example, changing a non-topic antecedent to the current topic may involve updating the [+/-TOPIC] feature of the relevant antecedents in memory. ${ }^{1}$ This dynamic feature updating can be considered a type of reanalysis. This raises the possibility that L2ers' difficulty in interpreting topic shift antecedents may be related to their reanalysis difficulties in syntactic ambiguity resolution rather than misapplication of retrieval cues. It is currently difficult to tease these issues apart, but

\footnotetext{
${ }^{1}$ Feature updating may also be required to implement certain c-command constraints (see Cunnings et al., 2015; Kush et al., 2015).
} 
investigating potential correlations between syntactic reanalysis and topic shift abilities in L2ers would be a useful avenue of research in this regard.

Some commentators (Jacob et al.; Malko et al.) emphasised how discourse plays a different role in syntactic ambiguity and anaphora resolution. Malko et al. argued that discourse effects in ambiguity resolution are unlikely a result of discourse-based retrieval cues, as it is difficult to conceive of how a particular retrieval cue may bias one interpretation of an ambiguous sentence over another. Instead, they argued discourse aids in choosing between competing interpretations. It is of course true that discourse effects in syntactic ambiguity resolution are of a different nature to those in anaphora, but retrieval may play a role in ambiguity resolution. In resolving ambiguous relative clauses for example (e.g. The journalist interviewed the assistant of the inspector who ...'; from Pan, Schimke \& Felser, 2015), although retrieval cues may not distinguish between the potential antecedents of 'who', the prior context may focus attention on one antecedent, which may then favour it being retrieved even if no specific cue distinguishes it from other items in memory. Note also that if ambiguity resolution here involves competitive consideration of the alternative interpretations, we might expect ambiguous sentences to have longer reading times than unambiguous sentences. There is however existing evidence of an 'ambiguity advantage' during both L1 and L2 processing, suggesting ambiguity resolution in this case does not involve competitive consideration of the different interpretations (Hopp, 2011; van Gompel, Pickering, Pearson \& Liversedge, 2005).

A number of commentators questioned why L2ers rely more heavily on particular types of retrieval cues (Gabriele et al.; Hamrick \& Ullman; Hopp; Kaan; Kaiser; Malko et al.; Omaki; Tremblay \& Coughlin). One possibility could be that cues derived from the lexical properties of nouns and verbs and morphosyntactic agreement features are relatively easy for highly proficient L2ers to utilise during processing because they are overtly marked on lexical items. Cues derived from the local syntactic and semantic context may also be fairly easy to utilise as they 
fall out naturally during parsing, but increasingly abstract cues, such as feature-based proxies required to implement c-command restrictions on linguistic dependencies, may not be weighted in exactly the same way as L1 speakers, as such cues are not obviously marked in the input.

In response to my claim that advanced L2ers overweight discourse-based cues to memory retrieval compared to L1 speakers, Kaiser (Kaiser) noted that an overreliance on discourse cues can be operationalized in two ways - either because L2ers over-weight discourse information, or because syntactic information is under-weighted. While the first account would predict an over-reliance on discourse-based cues only, the second would predict over-reliance on non-structural cues more generally. While I claimed that the existing evidence suggests discourse-based cues are more highly weighted during retrieval for L2ers, much of the evidence for this came from studies on anaphora resolution. Based on my arguments above however, that particularly more abstract retrieval cues may be difficult to implement during processing, it is possible that the second hypothesis should be entertained, such that an over-reliance on discourse cues is one symptom of L2ers under-weighting syntactic cues compared to L1 speakers. As this hypothesis allows for more clearly falsifiable predictions for a wider range of phenomena that do not only rely on discourse prominence, below I discuss ways in which this hypothesis may be tested in more detail.

The interference account that I proposed was primarily intended as an account of sentence processing rather than (L2) language acquisition. However, within this framework, language learning will involve acquiring the cues that guide retrieval. ${ }^{2}$ It is at least possible that the relative ease or difficulty with which advanced L2ers utilise different retrieval cues during parsing may be related to the relative ease or difficulty of learning different cues during

\footnotetext{
${ }^{2}$ Some commentators questioned how my proposal relates to L1 acquisition (Hamrick \& Ullman; Omaki). It is not possible to go into detail about this here, but for discussion of the role of interference in L1 acquisition, see Gerard (2016).
} 
acquisition. In this way, cues overtly marked in the input, such as those derived from lexical items, may be relatively easier to acquire than abstract cues that are not obviously marked in the input. Residual difficulty in applying more abstract syntactic cues during processing in even advanced L2ers may thus reflect earlier difficulty during acquisition. Although this possibility may provide additional motivation for why certain cues are weighted differently by L1 and L2 speakers, further research is required to investigate whether certain cues are indeed comparatively easier or more difficult for L2ers to utilise during processing at different levels of proficiency. $^{3}$

Based on my prediction that cues derived from lexical items should be comparatively easy to utilise during parsing, it is not immediately clear why overtly marked cues like agreement, especially grammatical gender, cause difficulty for L2 learners (a point also raised in commentaries and discussion of Phillips \& Ehrenhofer, 2015a, 2015b). Although agreement cues themselves (e.g. [+MASC]) should be easily derived from lexical items, the appropriate morphosyntactic licensing constraints on agreement are more abstract, and so may be more difficult for L2ers to implement in a nativelike way. I return to this issue of L2 difficulty in agreement when discussing the influence of lexical processing on syntactic parsing below.

\section{The interference account and other models of $L 2$ processing}

Some commentators asked for clearer predictions to distinguish the interference account from other models of L2 processing (Malko et al.; Hamrick \& Ullman). Others (Hopp; Juffs) questioned what role shallow processing (Clahsen \& Felser, 2006) may play in L2 parsing as

\footnotetext{
${ }^{3}$ The type of input and transfer may also play a role in how easy it is for particular cues to be acquired (see Hamrick \& Ullman; Omaki). As there is currently little data to examine these issues, I do not discuss them in more detail.
} 
opposed to retrieval interference. Below I compare the interference account to other theories of L2 parsing to elucidate ways in which the different theories can be dissociated empirically.

I claimed that L2 learners behave similarly to L1 speakers with regards to applying constraints on when a linguistic dependency may be formed, but differently with regards to constraints on what information is accessed once retrieval is initiated. My argument in this regard was based on evidence that L1 and L2 speakers apply syntactic constraints on when dependencies may be formed, which require well-specified syntactic structures to be applied, in a similar way (Bertenshaw, 2009; Felser, Cunnings, Batterham \& Clahsen, 2012; Omaki \& Schulz, 2011; Rodriguez, 2008). Evidence that L2ers violate such restrictions would be incompatible with my claim that L2ers construct well specified structures, but would be compatible with shallow processing (Clahsen \& Felser, 2006). A recent study by Boxell and Felser (2016) is relevant in this regard. Boxell and Felser reported that L2ers temporarily violate finiteness restrictions on the formation of parasitic gaps, and interpreted their results as indicating a delay in the construction of the relevant structure to license such gaps. While such results are compatible with shallow parsing, in the keynote article I argued that the weight of evidence from studies examining linguistic dependencies suggests L2ers largely construct similarly well-specified parses as L1 speakers. Further research is required to test the degree to which L2ers routinely violate the types of constraint studied by Boxell and Felser, and to examine whether nativelike behaviour here is ever possible. If such effects do indeed persist during L2 parsing, future research should aim to specify more precisely which aspects of structure building may remain 'shallow' at high levels of L2 proficiency.

I also claimed that the specific pattern of results from agreement attraction (e.g. Tanner, Nicol, Herschensohn \& Osterhout, 2012) suggest such effects are best characterised in terms of interference rather than shallow processing, but other patterns of results could implicate shallow parsing. For example, finding that L2ers temporarily consider a grammatical sentence such as 
'the key to the cabinets unsurprisingly was rusty' to be ungrammatical more often than L1 speakers (because of the local string 'the cabinets unsurprisingly was rusty') would implicate shallow parsing but would not be compatible with my interference account. ${ }^{4}$ The most obvious evidence instead for the interference account would be to show that L2ers exhibit either larger interference effects than L1 speakers, or patterns of interference not observed in L1 comprehension (e.g. Felser \& Cunnings, 2012). Such results are also not readily explained by capacity-based approaches to L1/L2 processing, given that in interference paradigms the amount of information stored in memory is similar across conditions, while the content of items in memory is manipulated.

One prediction of the interference account is that L2 speakers should exhibit larger facilitatory interference effects than L1 speakers. Two commentaries (Jacob et al.; Montrul \& Tanner) claimed existing studies suggest similar interference profiles in subject-verb agreement for L1 and L2ers (Lim \& Christianson, 2015; Tanner et al., 2012). Jacob et al. cited a number of production studies, and as such similar interference profiles here may highlight a dissociation between comprehension and production. Indeed, the role that shallow structures, cognitive capacity or memory interference may play in sentence production in L2 speakers is currently not well understood. For comprehension, Tanner et al. (2012) reported similarly-sized interference

\footnotetext{
${ }^{4}$ As discussed in Footnote 2 of the keynote article, this 'broken agreement' effect has been reported (e.g. Pearmutter Garnsey \& Bock, 1999). It was also found in a recent study on L2 processing (Jegerski, 2016). In both studies, the manipulated noun and critically verb were adjacent (e.g. the key to the cabinet(s) was rusty). Wagers et al. (2009) argue that broken agreement is confounded in such cases with the fact that plural nouns incur longer reading times than singulars, an effect that can spillover to following words. Studies examining broken agreement thus need to ensure this confound is avoided (for example, by adding in lexical material between the noun and critical verb).
} 
effects for L1 and L2 participants, although the results here may be complicated by the fact that L2ers showed smaller grammaticality effects in general. Lim and Christianson's (2015) study involved different procedures for L1 and L2 participants, so it may be difficult to draw strong conclusions with regards to potential differences in interference effects between the two groups, although L2ers did show numerically larger facilitatory interference effects in some reading time measures. More research is clearly required here to assess the interference account across a wider range of dependencies. This could include attraction paradigms testing agreement properties other than number, such as gender (as also noted by Keating). Interference paradigms that more clearly dissociate syntactic and semantic retrieval cues may also provide a fruitful avenue of future research. In each case, observing larger interference effects for L2 speakers would provide support for the interference account, but similar interference profiles for L1 and L2 speakers would suggest both groups implement retrieval cues similarly. Another potential line of research in this regard would be to further investigate cases in which L1 parsing appears comparatively robust against interference. One such case is reflexive binding, where facilitatory interference effects are not routinely observed (Cunnings \& Sturt, 2014; Dillon et al., 2013; Patil, Vasishth \& Lewis, 2016; Sturt, 2003). The interference account would predict L2 speakers should provide clearer evidence of interference in such cases.

Further examination of multiple-match inhibitory interference is also warranted. The conditions under which L1 speakers exhibit inhibitory interference is debated with some findings, such as multiple-match effects in anaphora, proving difficult to replicate (Badecker \& Straub, 2002; Chow, Lewis \& Phillips, 2014). Here it is worth noting that L2ers have shown inhibitory interference where L1 speakers do not (Felser, Sato \& Bertenshaw, 2009; Roberts, Gullberg \& Indefrey, 2008). Examining inhibitory interference in a wider variety of contexts, such as in paradigms similar to van Dyke (2007), would be useful in this regard (as also noted by 
Dillon). In this case, the interference account would predict larger inhibitory interference for L2 than L1 speakers.

For syntactic ambiguity resolution, I claimed that the primary source of L1/L2 differences relates to the persistence of an initially assigned interpretation in memory, rather than difficulty in constructing globally correct syntactic structures. Designs that tease apart these two issues (Slattery, Sturt, Christianson, Yoshida \& Ferreira, 2013) are key to testing this claim. Finding that L2ers have difficulty constructing globally correct parses would be compatible with shallow parsing. The interference account however predicts L1 and L2 speakers should behave similarly with regards to structural reanalysis, but that initially assigned interpretations should be more likely to persist for L2 than L1 speakers.

Hamrick and Ullman (Hamrick \& Ullman) contrasted my proposal to Ullman's (2015) declarative/procedural model, which claims that L2 speakers, especially at lower proficiencies, rely more on declarative storage of grammatical rules that are proceduralised in L1 speakers. I did not discuss in detail the contributions of declarative and procedural memory in cue-based models. In their computational implementation of cue-based parsing, Lewis and Vasishth (2005) assume grammatical rules are subserved by procedural memory, while lexical knowledge is stored in declarative memory. Memory chunks constructed during parsing are also stored and retrieved from declarative memory. As Lewis and Vasishth note, grammatical knowledge can in principle be spread across declarative and procedural memory in different ways. Part of their motivation for arguing that grammatical rules are proceduralised is because declarative retrieval of such knowledge would incur additional time. If L2ers rely more on declarative storage, their relatively slower processing than L1 speakers would thus in part reflect declarative retrieval of grammatical rules that are proceduralised in L1 speakers.

How declarative storage of grammatical rules may impact other aspects of sentence processing, such as interference, however is not currently well understood. While the 
declarative/procedural model focuses on the memory systems that underlie grammatical rules, the interference account that I proposed focuses on the types of information L1 and L2 speakers utilise to guide memory retrieval. Note that the declarative/procedural model in itself does not necessarily specify what knowledge is proceduralised during language acquisition. It is possible that a highly proficient L2 speaker might proceduralise an at least partially different set of grammatical rules than L1 speakers. Proficient L2 speakers with proceduralised grammatical rules may also implement retrieval cues differently to L1 speakers. We require both an understanding of how grammatical knowledge may be spread across declarative and procedural memory, as well as a clear understanding of the computational principles that underlie syntactic parsing and memory retrieval during comprehension, to gain a better understanding of the similarities and differences between L1 and L2 language processing.

Hamrick and Ullman (Hamrick \& Ullman) also questioned if cue-based parsing is only engaged for complex structures (highlighting examples 3, 9, 10 and 11 from the keynote article as being particularly complex). There is no reason why the model would not apply to sentences of varying complexity. Indeed, interference in agreement attraction (Wagers et al., 2009) is observed in sentences that on any metric would be considered quite simple. For three of the four examples highlighted by Hamrick and Ullman (examples 9, 10 and 11), L2 learners behave similarly to L1 speakers (Cunnings \& Felser, 2014; Felser et al., 2012; Omaki \& Schulz, 2011). I am unaware of any studies that have compared L1 and L2 speakers in the final example highlighted by Hamrick and Ullman (example 3), from van Dyke (2007). This study examined inhibitory interference, and as such the interference account predicts L2ers should show larger inhibitory interference effects in such cases.

Cue-based parsing distinguishes between the restricted set of items in the focus of attention and other non-focal items that require retrieval. While the size of the focus of attention during sentence processing is typically assumed to roughly correlate to maximal projections 
(Lewis \& Vasishth, 2005), Wagers (Wagers) considers that L1/L2 differences may be related to how focal attention is allocated during parsing. In this case, L2ers' increased susceptibility to interference may be a result of their need to retrieve information that L1 speakers maintain in focal attention. At present it is difficult to assess this hypothesis. Given that items in focal attention are accessed faster than those that require retrieval, future research that utilises methods such as the speed-accuracy trade-off paradigm to veridically measure retrieval speed (e.g. McElree, Foraker \& Dyer, 2003), would be useful in examining whether L1 and L2 speakers maintain different information in focal attention.

Futrell and Gibson (Futrell \& Gibson) proposed an alternative approach to L1/L2 processing in terms of noisy-channel parsing. According to this model, language processing involves error detection and correction by perceivers who assume the linguistic input is noisy in various ways. Perceivers may correct this noisy input based on syntactic probability or semantic/discourse plausibility (Gibson, Bergen \& Piantadosi, 2013). It is beyond the scope of this reply to fully assess this proposal. Futrell and Gibson's claim that L2 learners have less precise probabilistic models of syntax may be difficult to dissociate from my interference account. For example, my claim that L2ers weight syntactic and non-syntactic retrieval cues differently to L1 speakers may be difficult to dissociate empirically from the noisy-channel claim that L2 speakers have less precise models of L2 syntax. However, the claim that L2ers have less precise syntactic knowledge is broad, and I argued that there are in fact many cases in which L2 syntactic parsing is similar to L1 processing. It is unclear whether a noisy-channel model, in which L2ers generally have a less precise syntax and are more likely to consider alternative parses not directly compatible with the input, would also make nuanced predictions with regards to the conditions under which L2ers are able or unable to utilise syntactic knowledge in a nativelike way. 
Futrell and Gibson also discuss findings that L2 learners show greater persistence of initially-assigned interpretations during syntactic ambiguity resolution. In cases such as 'While Anna dressed the baby that was small and cute spit up in the bed', they argue that readers that assume noisy input might rationally assume a mistake (e.g. a missing 'it' at 'spit up in the bed'). In this way, if L2ers assume a higher noise rate than L1 speakers, they may be more likely to make corrections of their input. Even if L2ers have less precise models of L2 syntax, it is unclear why they would assume a higher noise rate in their input (assuming the input is from L1 speakers). The idea that L2ers are more likely to make corrections to the input also seems inconsistent with claims that L2ers have difficulty in making revisions to initial parsing commitments (Jacob \& Felser, 2016; Pozzan \& Trueswell, 2016). If L2ers are more likely to make corrections, the question of which corrections are made also needs to be addressed. Based only on the ease of correction to another syntactically and semantically plausible utterance, it is unclear why perceivers would edit the above example to include an additional word ('it') when the globally correct syntactic analysis requires a simpler (and plausible) edit that involves simply changing the verb 'dressed' to its intransitive interpretation. Persistence of the initially assigned interpretation in memory seems crucial for explaining misinterpretation in such cases.

Some commentators discussed how lexical access influences L2 sentence processing (Juffs; Hopp). Hopp (2015) investigated the interaction of lexical and syntactic processing in subject and object clefts. This study was based on work by Tily, Fedorenko and Gibson (2010) which showed that the object-cleft disadvantage, a type of inhibitory similarity-based interference (Gordon, Hendrick, \& Johnson, 2001), is delayed when the verb that triggers retrieval is low in frequency. Hopp (2015) showed that for L2ers, verb frequency exhibited a linear relationship with the difficulty associated with object-cleft sentences, while for L1 speakers such effects were only observed in comparatively lower frequency ranges. The results of both studies suggest that retrieval of the appropriate sentence chunks is not initiated until 
some amount of lexical processing is completed. While Hopp's results suggest the precise point in time at which the relevant lexical processing is completed differs for L1 and L2 speakers, both groups are similar in that lexical processing needs to be completed before memory retrieval operations are initiated. Thus, these results show similarity in when memory retrieval operations are initiated by both groups, in that some amount of lexical processing first needs to occur.

Hopp (Hopp) also claimed L2ers' predictive use of morphosyntactic gender relies on robust lexical representations (Hopp, 2013, 2016). Kaan (Kaan) also noted how L2ers' ability to use gender predictively is affected by whether the gender cues conflict in the L1 and L2 (Dussias, Valdés Kroff, Guzzardo Tamargo \& Gerfen, 2013). I agree that lexical representations likely play a role in L2 agreement processing. As noted above, agreement features are notoriously difficult for L2ers. Conflicting agreement cues between the languages an L2er may know may be one source of difficulty in implementing agreement cues during memory retrieval. More generally, less robust lexical representations may be a source of variability in L2ers' use of agreement. Consider (2), where detection of the ungrammaticality requires robust knowledge of both the relevant number of the verb and the sentence subject. Note that in cue-based retrieval, it is not the lexical item that is retrieved at the tail-end of the dependency, but rather the relevant sentence chunk in memory. Here I assume that how well information is retrieved from the lexicon (or decomposed during morphological processing), affects how well that feature is encoded in the relevant sentence chunk in memory. If the relevant feature is not robustly represented in the relevant lexical item, the feature may not be robustly encoded in the sentence representation, leading to less robust grammaticality effects in L2 learners (e.g. Tanner et al., 2012).

(2) The keys rather unsurprising was rusty. 
If L2ers' ability to robustly detect such ungrammaticalities during parsing is related to the initial lexical retrieval of the appropriate feature, L2ers reduced sensitivity to agreement may in part result from their increased reliance on whole-word lexical representations where L1 speakers are more likely to rely on morphological decomposition (Clahsen, Felser, Neubauer \& Sato, 2010; Ullman, 2015). I assume morphological decomposition allows robust encoding of relevant features in memory during parsing, while the representation of such features when based on lexical retrieval is more variable. That lexical retrieval of such features is less robust is evidenced in L1 processing. Allen, Badecker and Osterhout (2003) reported an ERP study showing that P600 effects to tense violations were of a similar onset and overall size for low and high frequency regular verbs. For irregular verbs however, P600 onset was later, and overall size smaller, for low frequency than high frequency verbs. These results suggest that for regular verbs, access to the relevant tense feature relied on morphological parsing, and as such was not affected by frequency. For irregular verbs however, access to the relevant tense feature relied on lexical retrieval, which was slower and less robust for lower frequency items. While Allen et al.'s study did not use an interference paradigm, the results suggest access to syntactic features is more robust when derived via morphological parsing than lexical retrieval. In this way, if L2ers are more likely to store morphologically complex words that are decomposed by L1 speakers, then their encoding of relevant (morphosyntactic) features in sentence chunks in memory may be less robust, and more dependent on the strength of the relevant lexical representation. While speculative, this hypothesis provides a novel way to test $\mathrm{L} 1 / \mathrm{L} 2$ differences in sentence processing that links work on L2 morphological processing with L2 sentence comprehension.

\section{Individual differences in monolingual and bilingual processing}

Some commentators highlighted how individual differences in language processing need to be considered from the perspective of both L2 and L1 speakers (Gabriele et al.; Hopp; Montrul \& 
Tanner). This is of course true, but the question remains whether individual differences in themselves can explain L1/L2 differences. Little is currently known about individual differences with regards to interference in L1 and L2 processing, and different types of interference may have differing sources. As noted by Kaan (Kaan) for example, retrieval interference in linguistic dependencies is different to revising garden-paths. Although both effects in some way rely on memory representations constructed during parsing, they likely rely on different underlying mechanisms that may correlate with different individual differences measures. Future work is required to investigate which individual differences measures correlate with different aspects of language processing, and whether L1 and L2 speakers are affected by such differences in a similar way.

Montrul and Tanner (Montrul \& Tanner) discussed how individual differences in 'capacity' measures need not implicate limits to cognitive capacity, in terms of the amount of information actively maintained in memory, but may instead index individual differences in controlled use of executive attention (Engle, 2002). This is of course true. For L2 research, perhaps the most widely adopted individual differences measure is reading span (Daneman \& Carpenter, 1980; Harrington \& Sawyer, 1992), which is commonly assumed to index capacitybased differences in the amount of information that can be held in memory at one time. However, individual differences in reading span likely reflect different executive control mechanisms, and interference may play a role in explaining performance in this task. When studying individual differences, we need a clear understanding of what underlying cognitive mechanisms each task indexes, and also a clear theoretical link to how that mechanism affects language processing. Currently, these links are unfortunately sometimes lacking.

Keating (Keating) highlights individual differences in L2 proficiency and questions studies purporting to examine 'advanced' learners which include participants with lower proficiency (see also Hamrick \& Ullman). I agree that conclusions drawn about high levels of 
proficiency should be restricted to studies testing advanced learners, but it is worth noting that even lower proficiency learners can behave similarly to L1 speakers for some phenomena. Cunnings, Fotiadou and Tsimpli (2016) for example recently found that L2 learners, ranging from 'lower intermediate' to 'very advanced' proficiency, interpret subject pronouns in English similarly to L1 speakers. Future work examining L2 learners of differing proficiency would be one way to elucidate which types of retrieval cues may be comparatively easier or more difficult to acquire and process in a nativelike way.

Other commentators highlighted different types of bilingualism, and noted how the different languages a bilingual may know may influence how each language is processed (Dussias, Beatty-Martínez \& Perrotti; Gabriel et al.; Tremblay \& Coughlin). Dussias et al. cited evidence that the L2 may influence L1 parsing. The data here investigated relative clause ambiguities, where multiple interpretations are grammatical and preferences are known to vary. Whether similar effects are observed for less variable phenomena, such as whether an L1 English speaker would consider long-distant reflexive binding after learning an L2 that allows such interpretations, is an open question for future research. Tremblay and Coughlin raised the issue of whether L2 effects are truly L2 effects or rather bilingualism effects, and noted that studies of early bilinguals are needed to test this possibility. I agree but very little is currently known about this issue. It is unclear how bilingualism by itself could explain some of the data however, such as the results of Felser and Cunnings (2012), where reflexives in the learners' L1 have similar constraints as the L2. While early bilinguals were not tested in this study, the prediction in this case would be that early bilinguals should behave like L1 but not L2 English speakers. Further research is again needed to tease apart these issues.

\section{Conclusion}


I have argued for an account of the similarities and differences in native and non-native language processing that focuses on the memory operations that subserve language comprehension. Further systematic examination of different linguistic phenomena is required to refine our understanding of which properties of a language are relatively easy or difficult to acquire, and to test whether or not nativelike parsing is possible in late L2 acquisition. It is hoped that the interference account that I proposed provides one way of examining these issues in both L2 learners and other types of bilingual populations, to help us gain a better understanding of monolingual and bilingual sentence processing. 


\section{$\underline{\text { Acknowledgements }}$}

I would like to thank the commentators for their in-depth discussion of the target article. It was impossible to fully do justice to all the comments that were made. I would also like to thank the editor for helpful comments on both the keynote article and my response. 


\section{$\underline{\text { References }}$}

Alcocer, P. and Phillips, C. (2012). Using relational syntactic constrains in content-addressable memory architectures for sentence processing. Unpublished manuscript, University of Maryland.

Allen, M., Badecker, W. \& Osterhout, L. (2003). Morphological analysis during sentence processing. Language and Cognitive Processes, 18, 405-430.

Badecker, W., \& Straub, K. (2002). The processing role of structural constraints on the interpretation of pronouns and anaphors. Journal of Experimental Psychology: Learning, Memory and Cognition, 28, 748-769.

Bertenshaw, N. (2009). The application of binding constraints by Japanese L2 learners of English. Unpublished PhD dissertation. University of Essex, UK.

Boxell, O. \& Felser, C. (2016). Sensitivity to parasitic gaps inside subject islands in native and non-native sentence processing. Bilingualism: Language and Cognition. DOI: https://doi.org/10.1017/S1366728915000942

Clahsen, H. \& Felser, C. (2006). Grammatical processing in language learners. Applied Psycholinguistics, 27, 3-42.

Chomsky, N. (1981). Lectures on Government and Binding. Dordrecht: Foris.

Chow, W-Y., Lewis S., \& Phillips, C. (2014). Immediate sensitivity to structural constraints in pronoun resolution. Frontiers in Psychology, 5, 630. DOI: http://dx.doi.org/10.3389/fpsyg.2014.00630

Clahsen, H., Felser, C., Neubauer, K. \& Sato, M. (2010). Morphological structure in native and nonnative language processing. Language Learning, 60, 21-43. 
Cunnings, I. Parsing and working memory in bilingual sentence processing. Bilingualism: Language and Cognition. DOI: http://dx.doi.org/10.1017/S1366728916000675

Cunnings, I. \& Felser, C. (2013). The role of working memory in the processing of reflexives. Language and Cognitive Processes, 28, 188-219.

Cunnings, I. \& Felser, C. (2014). Plausibility and filled gap effects in native and non-native sentence processing. Poster presented at AMLaP 2014, University of Edinburgh, UK.

Cunnings, I., Fotiadou, G. \& Tsimpli, I. (2016). Anaphora resolution and reanalysis during L2 sentence processing: Evidence from the visual world paradigm. Studies in Second Language Acquisition. DOI: http://dx.doi.org/10.1017/S0272263116000292

Cunnings, I., Patterson, C. \& Felser, (2015). Structural constraints on pronoun binding and coreference: Evidence from eye-movements during reading. Frontiers in Psychology, 6, 840. DOI: http://dx.doi.org/10.3389/fpsyg.2015.00840

Cunnings, I. \& Sturt, P. (2014). Coargumenthood and the processing of reflexives. Journal of Memory and Language, 75, 117-139.

Daneman, M. \& Carpenter, P. (1980). Individual differences in working memory and reading. Journal of Verbal Learning and Verbal Behavior, 19, 450-466.

Dillon, B. A short discourse on reflexives: A reply to Cunnings (2016). Bilingualism: Language and Cognition. DOI: https://doi.org/10.1017/S1366728916000973

Dillon, B., Mishler, A., Sloggett, S., \& Phillips, C. (2013). Contrasting intrusions profiles for agreement and anaphora: Experimental and modelling evidence. Journal of Memory and Language, 69, 85-103. 
Dussias, P., Beatty-Martínez, A. \& Perrotti, L. Susceptibility to interference affects the second and the first language. Bilingualism: Language and Cognition. DOI: http://dx.doi.org/10.1017/S1366728916001024

Dussias, I., Valdés Kroff, J., Guzzardo Tamargo, R. \& Gerfen, C. (2013). When gender and looking go hand in hand. Grammatical gender processing in L2 Spanish. Studies in Second Language Acquisition, 35, 353-3887.

Engle, R. (2002). Working memory capacity as executive attention. Current Directions in Psychological Science, 11, 19-23.

Felser, C. \& Cunnings, I. (2012). Processing reflexives in English as a second language: The role of structural and discourse-level constraints. Applied Psycholinguistics, 33, 571-603.

Felser, C., Cunnings, I., Batterham, C., \& Clahsen, H. (2012). The timing of island effects in nonnative sentence processing. Studies in Second Language Acquisition, 34, 67-98.

Felser, C., Sato, M., \& Bertenshaw, N. (2009). The on-line application of Binding Principle A in English as a second language. Bilingualism: Language and Cognition, 12, 485-502.

Futrell, R. \& Gibson, E. L2 processing as noisy channel language comprehension. Bilingualism: Language and Cognition. DOI: http://dx.doi.org/10.1017/S1366728916001061

Gibson, E., Bergen, L. \& Piantadosi, S. (2013). Rational integration of noisy evidence and prior semantic expectations in sentence interpretation. Proceedings of the National Academy of Sciences, 110, 8051-8056.

Gabriele, A., Fiorentino, R. \& Covey, L. Understanding the symptoms and sources of variability in second language sentence processing. Bilingualism: Language and Cognition. DOI: http://dx.doi.org/10.1017/S1366728916000961 
Gerard, J. (2016). The acquisition of adjunct control: Grammar and processing. Unpublished doctoral thesis, University of Maryland.

Gordon, P., Hendrick, R., \& Johnson, M. (2001). Memory interference during sentence processing. Psychological Science, 13, 425-430.

Hamrick, P. \& Ullman, M. A neurocognitive perspective on retrieval interference in L2 sentence processing. Bilingualism: Language and Cognition. DOI: http://dx.doi.org/10.1017/S136672891600081X

Harrington, M. and Sawyer, M. (1992). Working memory capacity and L2 reading skill. Studies in Second Language Acquisition, 14, 25-38.

Hopp, H. Individual differences in L2 parsing and lexical representations. Bilingualism: Language and Cognition. DOI: http://dx.doi.org/10.1017/S1366728916000821

Hopp, H. (2011). Immediate syntactic ambiguity resolution in the L2: An eyetracking study. Talk presented at the $8^{\text {th }}$ International Symposium on Bilingualism, Oslo, Norway.

Hopp, H. (2013). Grammatical gender in adult L2 acquisition: Relations between lexical and syntactic variability. Second Language Research, 29, 33-56.

Hopp, H. (2016). The timing of lexical and syntactic processes in second language sentence comprehension. Applied Psycholinguistics, 37, 1253-1280.

Hopp, H. (2016). Learning (not) to predict: Grammatical gender processing in adult L2 acquisition. Second Language Research, 32, 277-307.

Jacob, G. \& Felser, C. (2016). Reanalysis and semantic persistence in native and non-native garden-path recovery. The Quarterly Journal of Experimental Psychology, 69, 907-925. 
Jacob, G., Lago, S. \& Patterson, C. L2 processing and memory retrieval: Some empirical and conceptual challenges. Bilingualism: Language and Cognition. DOI: http://dx.doi.org/10.1017/S1366728916000948

Jegerski, J. (2016). Number attraction effects in near-native Spanish sentence comprehension. Studies in Second Language Acquisition, 38, 5-33.

Juffs, A. Construct operationalization, L1 effects, and context in second language processing. Bilingualism: Language Cognition. DOI: https://doi.org/10.1017/S1366728916000900

Kaan, E. Susceptibility to interference: Underlying mechanisms, and implications for prediction. Bilingualism: Language Cognition. DOI: http://dx.doi.org/10.1017/S1366728916000894

Kaiser, E. On the role of discourse-level information in second-language sentence processing. Bilingualism: Language Cognition. DOI: https://doi.org/10.1017/S1366728916001012

Keating, G. L2 proficiency matters in comparative L1/L2 processing research. Bilingualism: Language and Cognition. DOI: http://dx.doi.org/10.1017/S1366728916000912

Kush, D. (2013). Respecting relations: Memory access and antecedent retrieval in incremental sentence processing. Unpublished doctoral thesis, University of Maryland.

Kush, D. Lidz, J. \& Phillips, C. (2015). Relation-sensitive retrieval: Evidence from bound variables pronouns. Journal of Memory and Language, 82, 18-40.

Lewis, R. \& Vasishth, S. (2005). An activation-based model of sentence processing as skilled memory retrieval. Cognitive Science, 29, 375-419. 
Lewis, R., Vasishth, S. \& Van Dyke, J. (2006). Computation principles of working memory in sentence comprehension. Trends in Cognitive Sciences, 10, 447-454.

Lim, L. \& Christianson, K. (2015). Second language sensitivity to agreement errors: Evidence from eye movements during comprehension and translation. Applied Psycholinguistics, $36,1283-1315$.

Malko, A., Ehrenhofer, L. \& Phillips, C. Theories and frameworks in second language processing. Bilingualism: Language and Cognition. DOI: https://doi.org/10.1017/S1366728916001000

McElree, B., Foraker, S., \& Dyer, L. (2003). Memory structures that subserve sentence comprehension. Journal of Memory and Language, 48, 67-91.

McDonald, J. (2006). Beyond the critical period: Processing-based explanations for poor grammaticality judgement performance by late second language learners. Journal of Memory and Language, 55, 381-401.

Montrul, S. \& Tanner, D. Individual differences and retrieval interference in L2 processing. Bilingualism: Language Cognition. DOI: http://dx.doi.org/10.1017/S136672891600095X

Omaki, A. Linking learning and parsing in bilingual sentence processing. Bilingualism: Language and Cognition. DOI: http://dx.doi.org/10.1017/S1366728916000985

Omaki, A. \& Schulz, B. (2011). Filler-gap dependencies and island constraints in secondlanguage sentence processing. Studies in Second Language Acquisition, 33, 563-588.

Pan, H., Schimke, S. \& Felser, C. (2015). Referential context effects in non-native relative clause ambiguity resolution. International Journal of Bilingualism, 19, 298-313. 
Patil, U., Vasishth, S. \& Lewis, R. (2016). Retrieval interference in syntactic processing: The case of reflexive binding in English. Frontiers in Psychology, 7, 329. DOI: http://dx.doi.org/10.3389/fpsyg.2016.00329

Pearlmutter. N., Garnsey, S. \& Bock, K. (1999). Agreement processes in sentence comprehension. Journal of Memory and Language, 41, 427-456.

Phillips, C. \& Ehrenhofer, L. (2015). The role of language processing in language acquisition. Linguistic Approaches to Bilingualism, 5, 409-453.

Phillips, C. \& Ehrenhofer, L. (2015). Learning obscure and obvious properties of language. Linguistic Approaches to Bilingualism, 5, 545-555.

Pozzan, L. \& Trueswell, J. (2016). Second language processing and revision of garden-path sentences: a visual world study. Bilingualism: Language and Cognition, 19, 636-643.

Reinhart, T. (1983). Constraints on variables in syntax. London: Croom Helm.

Roberts, L., Gullberg, M., \& Indefrey, P. (2008). Online pronoun resolution in L2 discourse: L1 influence and general learner effects. Studies in Second Language Acquisition, 30, 333357.

Rodriguez, G. (2008). Second language sentence processing: Is it fundamentally different?. Unpublished PhD dissertation. University of Pittsburgh, USA.

Sorace, A. \& Filiaci, F. (2006). Anaphora resolution in near-native speakers of Italian. Second Language Research, 22, 339-368.

Slattery, T., Sturt, P., Christianson, K., Yoshida, M., \& Ferreira, F. (2013). Lingering misinterpretations of garden path sentences arise from competing syntactic representations. Journal of Memory and Language, 69, 104-120. 
Sturt, P. (2003). The time-course of the application of binding constraints in reference resolution. Journal of Memory and Language, 48, 542-562.

Tanner, D., Nicol, J., Herschensohn, J., \& Osterhout, L. (2012) Electrophysiological markers of interference and structural facilitation in native and nonnative agreement processing. In Biller, A., Chung, A., \& Kimball, A. (eds.), Proceedings of the 36th Boston University Conference on Language Development, pp. 594-606. Somerville: Cascadilla.

Tily, H., Fedorenko, E. \& Gibson, E. (2009). The time-course of lexical and structural processes in sentence comprehension. Quarterly Journal of Experimental Psychology, 63, 910-927.

Tremblay, A. \& Coughlin, C. Cue-weighting mechanism and bilingualism. Bilingualism: Language and Cognition. DOI: http://dx.doi.org/10.1017/S1366728916001036

Ullman, M. (2015). The declarative/procedural model: A neurobiologically motivated theory of first and second language. In VanPatten, B. \& Williams, J. (eds.), Theories in Second Language Acquisition: An Introduction (2 ${ }^{\text {nd }}$ edition). New York: Routledge.

Van Dyke, J. (2007). Interference effects from grammaticality unavailable constituents during sentence processing. Journal of Experimental Psychology: Learning, Memory and Cognition, 33, 407-430.

Van Gompel, R., Pickering, M., Pearson, J. \& Liversedge, S. (2005). Evidence against competition during syntactic ambiguity resolution. Journal of Memory and Language, 52, 284-307.

Wagers., M. Sources of variability in linguistic memory systems. Bilingualism: Language and Cognition. DOI: http://dx.doi.org/10.1017/S1366728916000997

Wagers, M., Lau, E., \& Phillips, C. (2009). Agreement attraction in comprehension: representations and processes. Journal of Memory and Language, 61, 206-237. 